\title{
STRUKTUR DAN KOMPOSISI JENIS TUMBUHAN DI SEKITAR PERSARANGAN BURUNG PINTAR (Amblyornis inornatus).
}

\section{(Structure and Composition of Tree Species Surrounding Nested Habitat of 'Burung Pintar' [Amblyornis inornatus])}

\author{
Dewi Pratiwi ${ }^{1}$ Srihartati Harto ${ }^{1 凶}$ dan Rina Nelly Jowei ${ }^{1}$ \\ Jurusan Kehutanan, Fakultas Kehutanan Universitas Papua Manokwari, Papua Barat, \\ 98314. Tlp/Fax: +62986211065. \\ ${ }^{\square}$ Penulis Korespondensi: Email: srihartatiharto@gmail.com \\ Diterima: 3 Feb 2018| Disetujui: 1 Apr 2018
}

\begin{abstract}
Abstrak
Penelitian ini bertujuan untuk mengetahui struktur dan komposisi jenis tumbuhan disekitar persarangan burung pintar (Amblyornis inornatus). Penelitian ini dilakukan sekitar persarangan burung pintar di Kampung Syoubri. Metode pengambilan contoh untuk mengetahui struktur dan komposisi disekitar persarangan burung pintar adalah metode petak dengan menggunakan petak ganda, yang ukuran petak contohnya disesuaikan dengan tingkat pertumbuhan. Hasil penelitian memperlihatkan bahwa pada sekitar persarangan burung pintar (Amblyornis inornatus) terdapat 15 spesies tumbuhan dari 13 famili, dengan total jumlah individu yang ditemukan mulai dari fase semai, pancang, tiang dan pohon sebanyak 118 individu. Komposisi jumlah jenis terdiri dari: 9 jenis tingkat semai, 5 jenis untuk tingkat pancang, 3 jenis untuk tingkat tiang, dan 11 jenis untuk tingkat pohon. Semua fase pertumbuhan ini didominasi oleh Syzygium sp., Syzygium sp. memiliki INP tertinggi pada semua fase pertumbuhan: semai $(59,01 \%)$, pancang $(112,50 \%)$, tiang $(202 \%)$ dan pohon $(47,68 \%)$. Sementara nilai INP terendah pada tingkat semai adalah Ficus sp. (7,50\%), tingkat pancang masing-masing Rodamnia sp., Elaeocarpus altiscatus, dan Sterculia parkinsonii dengan nilai INP yang sama (18,75\%), tingkat tiang Litocarpus sp. dan Rodamnia sp. masing-masing (25,00\%), dan tingkat pohon Elaeocarpus altiscatus $(12,21 \%)$.
\end{abstract}

Kata kunci: Struktur dan komposisi pohon, persarangan burung, burung pintar, indeks nilai penting.

\begin{abstract}
This study aims to reveal forest structure and composition of tree that was closely associated to 'burung pintar' (Amblyornis inornatus) nested habitat. The study was focused on the closed area of nested place. In conducting the study, plotted method by using doubled plot design has been chosen to determine density, dominancy, and frequency of the forest structure and composition. The plotted size was adjusted to the surrounding growing rate. The result pointed out that in the surrounding nested area, there were 15 species found from 13 families with a total numbers of 118 individual trees in all growing stages (seedling, sapling, pole, and tree). In terms of species composition consisted of : 9 at seedling stage, 5 at sapling stage, 3 at pole stage, and 11 at tree stage. The whole growing stages was dominated by Syzygium sp. The species had a highest important value index
\end{abstract}


score over all stages: seedling (59.01\%), sapling (112.50\%), pole (202\%), and tree $(47.68 \%)$. On the flip side, the lowest important value index score at seedling stage was Ficus sp. (7.50\%), at sapling was Rodamnia sp., Elaeocarpus altiscatus, and Sterculia parkinsonii with the same important value index score of $18.75 \%$, at pole stage was Litocarpus sp. and Rodamnia sp., with the score of $25,00 \%$, and at tree stage was Elaeocarpus altiscatus with the score of $12.21 \%$.

Keywords: Tree structure and composition, nested area, 'burung pintar', important value index

\section{PENDAHULUAN}

Analisis komunitas tumbuhan merupakan suatu metode yang mempelajari susunan atau komposisi jenis dan struktur vegetasi. Di dalam suatu ekologi hutan, satuan vegetasi yang dipelajari berupa komunitas tumbuhan yang merupakan asosiasi konkret dari semua spesies tumbuhan yang menempati suatu habitat. Menurut Indriyanto (2006), tujuan yang ingin dicapai dalam analisis komunitas adalah untuk mengetahui komposisi spesies dan struktur komunitas tumbuhan pada suatu wilayah yang dipelajari.

Komposisi dan struktur komunitas menggambarkan tingkat kelimpahan suatu spesies dalam suatu komunitas, distribusi individu antar spesies, dan pengaruh spesies terhadap keseimbangan sistem dan stabilitas komunitas (Soegianto 1994). Selain itu juga struktur dan komposisi vegetasi merupakan salah satu parameter yang harus diperhatikan dalam kegiatan pengelolaan hutan. Qureshi (1963) dalam Ramandey (1999) mengemukakan bahwa pengenalan tipe struktur dan komposisi vegetasi sangat penting bagi kegiatan kehutanan dalam aspek ekologi dan sebagai dasar dalam menentukan teknik silvikultur yang akan dipilih dan digunakan.

Papua merupakan salah satu wilayah dengan tingkat biodiversity tertinggi di dunia. Secara administrasi wilayah Papua terbagi menjadi Provinsi Papua dan Papua Barat. Provinsi Papua dan Papua Barat memiliki beragam habitat dan tipe ekosistem mulai dari ekosistem dataran rendah hingga ekosistem nifal.

Cagar Alam Pegunungan Arfak merupakan salah satu tipe ekosistem pegunungan tinggi di Provinsi Papua Barat yang mempunyai luas \pm 68.325 ha (Badan Pusat Statistik Papua Barat 2018). Cagar Alam ini memiliki beragam jenis vegetasi dan menjadi habitat penting bagi beberapa satuan endemik, termasuk berbagai jenis burung endemik. Burung Cendrawasih Hitam Ekor Panjang (Astrapia nigra), Cenderawasi Belah Rotan (Cicinnurus magnificus), Burung Maleo (Aepypodius arfakianus), dan Burung Pintar (Amblyornis inornatus) merupakan contoh jenis-jenis burung endemik yang ada dikawasan Pegunungan Arfak. Keberadaan dan aktifitas burung-burung ini sangat dipengaruhi oleh kondisi vegetasi di sekitaran habitat burung tersebut. Habitat hutan dengan kondisi vegetasi yang baik akan menjadi habitat yang sesuai untuk satwa liar (Indriyanto 2006). Penelitian ini bertujuan mengetahui struktur dan komposisi jenis tumbuhan disekitar persarangan burung pintar di Kampung Syoubri. 


\section{METODE PENELITIAN}

Penelitian ini dilakukan di Kampung Syoubri Distrik Warmare Kabupaten Manokwari Provinsi Papua Barat selama \pm 1 bulan dari Oktober s/d November 2015. Titik pengambilan data struktur dan komposisi vegetasi difokuskan pada daerah sekitar persarangan burung pintar (Amblyornis inornatus). Objek dalam penelitian ini adalah semua jenis tumbuhan mulai dari tingkat semai, pancang, tiang, sampai pohon di lokasi penelitian di sekitaran persarangan burung pintar.

\section{Metode dan Teknik Penelitian}

Metode yang digunakan dalam penelitian ini adalah metode deskriptif dengan pendekatan kualitatif dan kuantitatif (Kusmana 2001). Metode deskripsi

kuantitatif dilakukan dalam beberapa tahap penelitian yaitu: penelitian lapangan dan analisis data. Selanjutnya metode deskripsi kualitatif adalah penjelasan hasil analisis data dengan melakukan kajian pustaka terkait struktur dan komposisi. Teknik yang digunakan dalam pengambilan data adalah teknik sampling. Variabel yang diamati dalam penelitian ini terbagi menjadi dua, yaitu variabel utama dan variabel penunjang. Variabel utama meliputi struktur dan komposisi jenis tumbuhan disekitar persarangan. Selanjutnya variabel penunjang meliputi keadaan umum lokasi penelitian.

\section{Tahapan penelitian}

Penelitian dilakukan dengan prosedur sebagai berikut :

1. Penentuan lokasi penelitian

Lokasi penelitian ditentukan berdasarkan wilayah prevalensi bagi burung pintar di Kampung Syoubri, Distrik Warmare yang kemudian disebut sebagai titik pengamatan, luas titik pengamatan ditentukan $1 \mathrm{Ha}(100$ $\times 100 \mathrm{~m})$.

2. Pembuatan plot pengamatan

Pembuatan plot pengamatan ini dibuat dengan pertimbangan kondisi topografi dan kelerengan. Untuk pengambilan contoh vegetasi, metode yang digunakan adalah metode petak ganda, jumlah petak contoh yang dibuat adalah sebanyak 4 dan disusun sesuai arah mata angin. Ukuran tiap plot contoh disesuaikan dengan tingkat pertumbuhan.

3. Pengambilan data

Pengambilan data dilakukan pada plot-plot yang dibentuk disesuaikan dengan ukuran pertumbuhan. Pengambilan data dilakukan sbb:

a. Pengambilan data awal yaitu pada tingkat pohon dengan ukuran petak $20 \times 20 \mathrm{~m}$, data yang diambil yaitu nama jenis, $\varnothing$ (diameter), tbc (tinggi bebas cabang) dan tt (tinggi total).

b. Pengambilan data pada fase tiang dengan ukuran petak $10 \times 10 \mathrm{~m}$, data yang diambil yaitu nama jenis, $\varnothing$ (diameter), tbc (tinggi bebas cabang), dan tt (tinggi total).

c. Pengambilan data pada fase pancang dengan ukuran petak $5 \times 5$ $\mathrm{m}$, data yang diambil yaitu nama jenis dan jumlah jenis.

d. Pengambilan data pada fase semai dengan ukuran petak $2 \times 2 \mathrm{~m}$, data yang diambil yaitu nama jenis dan jumlah jenis.

\section{Pengumpulan Data}

Data yang dikumpulkan dibagi menjadi dua yaitu data primer dan data 
sekunder. Data primer meliputi: struktur dan komposisi jenis yang ditentukan berdasarkan frekuensi, kerapatan, dominansi, dan INP. Sedangkan data sekunder meliputi: tempat tumbuh, topografi, tanah, keadaan umum lokasi (kampung) dan iklim (suhu dan kelembaban).

\section{Pengolahan Data}

Data yang dikumpulkan diolah berdasarkan tingkat pertumbuhan meliputi jenis, famili dan jumlah individu serta jumlah plot pengamatan, kemudian dihitung dengan rumus atau persamaan menurut Kusmana (1997) sebagai berikut;

\section{a. $\operatorname{Kerapatan}(K)$ \\ Kerapatan $(\mathrm{K})=\frac{\text { jumlah individu suatu jenis }}{\text { luas plotcontoh }}$ \\ Kerapatan relatif $(\mathrm{KR})=$ \\ $\frac{\text { kerapatan suatu jenis }}{\text { kerapatan seluruh jenis }} \times 100 \%$}

\section{b. Frekuensi (F)}

Frekuensi $(\mathrm{F})=$

jumlah plot ditemukan suatu jenis

jumlah seluruh plotcontoh

\section{Frekuensi relatif $(F R)=$ $\frac{\text { frekuensi suatu jenis }}{\text { frekuensi seluruh jenis }} \times 100 \%$}

\section{c. Dominansi}

\section{Dominansi $=$}

jumlah luas bidang dasar (LBD) suatu jenis luas plot

\section{Dominansi relatif $=$}

dominansi dari suatu jeni

jumlah luas seluruh dominansi.

\section{$100 \%$}

a. Indeks Nilai Penting (INP)

Nilai Penting Tingkat Semai dan Pancang $=$ KR $(\%)+$ FR $(\%)$ Nilai

Penting Tingkat Tiang dan Pohon $=\mathrm{KR}$ $(\%)+$ FR $(\%)+$ DR $(\%)$

Untuk mendapatkan nilai luas bidang dasar pada perhitungan dominansi dapat digunakan rumus sebagai berikut :

$$
\operatorname{LBD}=1 / 4 \pi(\mathrm{d} / 100)^{2}
$$

Dimana :

$$
\begin{aligned}
\text { LBD } & =\text { Luas Bidang Datar } \\
\pi & =3,14 \\
\mathrm{~d} & =\text { Diameter }(\mathrm{cm}) .
\end{aligned}
$$

\section{Analisis Data}

Analisis yang digunakan dalam penelitian ini adalah data yang di peroleh di lapangan dianalisis secara deskriptif serta disajikan dalam bentuk tabel dan gambar.

\section{HASIL DAN PEMBAHASAN}

\section{HASIL}

\section{Komposisi Jenis}

Hasil penelitian menunjukkan bahwa jenis tumbuhan yang terdapat di sekitar persarangan burung pintar di kampung Syoubri terdiri dari 15 spesies yang dikelompokan ke dalam 13 famili. Total jumlah tumbuhan yang ditemukan mulai dari fase semai, pancang, tiang dan pohon sebanyak 118 individu. Nama spesies dan famili disajikan pada Tabel 1. Jumlah jenis yang ditemukan dibagi menjadi beberapa fase, yaitu tingkat semai, pancang tiang, dan pohon. Hasil pengamatan memperlihatkan bahwa untuk tingkat semai ditemukan 9 jenis 
diantaranya Syzygium sp., Elaeocarpus altiscatus, Drypethes sp., Pouteria sp., Flindersia sp., Rodamnia sp., Ficus sp.,
Dysoxyllum acutangulum dan Sterculia parkinsonii.

Tabel 1. Daftar nama jenis tumbuhan yang terdapat di sekitar persarangan burung pintar.

\begin{tabular}{|c|c|c|c|c|}
\hline No. & Nama Jenis & Nama Lokal & $\begin{array}{c}\text { Nama } \\
\text { Dagang }\end{array}$ & Famili \\
\hline 1. & Aglaia sp. & - & Pasak & Meliaceae \\
\hline 2. & Dacrioides sp. & - & Kenari & Burseraceae \\
\hline 3. & Drypethes sp. & - & - & Euphorbiaceae \\
\hline 4. & Dysoxyllum acutangulum & Bregah & Cempaga & Meliaceae \\
\hline 5. & Elaeocarpus altiscatus & Bipia & Jenitri & Elaeocarpuceae \\
\hline 6. & Ficus sp. & Asara & Beringin & Moraceae \\
\hline 7. & Flindersia sp. & Bingwauga & - & Rutaceae \\
\hline 8. & Litocarpus sp. & Pigana & - & Fagaceae \\
\hline 9. & Podocarpus sp. & Ceia/kayu cina & Kayu cina & Podocarpaceae \\
\hline 10. & Prunus sp. & Buwoa & - & Rosaceae \\
\hline 11. & Pouteria sp. & - & - & Sapotaceae \\
\hline 12. & Rodamnia sp. & - & - & Myrtaceae \\
\hline 13. & Syzygium sp. & Bituga & Jambu & Myrtaceae \\
\hline 14. & Sterculia parkinsonii & Bumbuwea & Kelumpang & Malvaceae \\
\hline 15. & Vitex pinnata & Binjena & Gofasa & Verbenaceae \\
\hline
\end{tabular}

Sumber: Data Primer, 2015

Tingkat pancang jumlah jenis yang ditemukan sebanyak 5 jenis antara lain Syzygium sp., Rodamnia sp., Pouteria sp., Elaeocarpus altiscatus dan Sterculia parkinsonii. Tingkat tiang jumlah jenis yang ditemukan sebanyak 3 jenis yaitu Syzygium sp., Litocarpus sp. dan Rodamnia sp. dan pada tingkat pohon memiliki jumlah jenis 11 diantaranya Prunus sp., Dysoxyllum acutangulum, Pouteria sp., Syzygium sp., Drypethes sp., Dacrioides sp., Elaeocarpus altiscatus, Sterculia parkinsonii, Rodamnia sp., Podocarpus sp. dan Vitex pinnata.

Komposisi jenis tumbuhan yang ditemukan pada sekitar persarangan burung pintar (Amblyornis inornatus) menunjukan hasil yang berbeda-beda pada setiap tingkatan pertumbuhan.
Jumlah jenis pada fase pohon lebih banyak bila dibandingkan dengan fasefase lain. Jumlah jenis terendah terdapat pada fase tiang.

\section{Struktur Jenis}

Struktur jenis tumbuhan pada sekitar persarangan burung pintar dikaji menggunakan parameter kuantitatif, yaitu dengan menelusuri Kerapatan Relatif (KR), Frekuensi Relatif (FR), dan Dominansi Relatif (DR) dari masingmasing individu per satuan luas petak ukur pengamatan. Untuk menyatakan tingkat dominansi (tingkat penguasaan) pada sekitar persarangan burung pintar (Amblyornis inornatus) dikaji melalui Indeks Nilai Penting (INP).

Dalam setiap fase pertumbuhan masing-masing individu memiliki tingkat dominansi yang berbeda-beda mulai dari 
tingkat semai, pancang, tiang, dan pohon, hal tersebut dapat dilihat pada perbedaan INP masing-masing individu pada setiap fase pertumbuhan berikut:

a. Tingkat Semai
Hasil dari analisis vegetasi untuk tingkat semai pada sekitar persarangan burung pintar (Amblyornis inornatus) disajikan pada Tabel 2.

Tabel 2. Jenis, penyebaran dan indeks nilai penting vegetasi tingkat semai pada sekitar persarangan burung pintar.

\begin{tabular}{llccccc}
\hline No. & Nama Jenis & K & $\begin{array}{c}\text { KR } \\
\mathbf{( \% )}\end{array}$ & F & $\begin{array}{c}\text { FR } \\
\mathbf{( \% )}\end{array}$ & INP \\
\hline 1. & Syzygium sp. & 0.22 & 35.48 & 1.00 & 23.53 & 59.01 \\
2. & Elaeocarpus altiscatus & 0.1 & 16.13 & 1.00 & 23.53 & 39.66 \\
3. & Rodamnia sp. & 0.09 & 14.52 & 0.50 & 11.76 & 26.28 \\
4. & Drypethes sp. & 0.05 & 8.06 & 0.50 & 11.76 & 19.83 \\
5. & Flindersia sp. & 0.05 & 8.06 & 0.25 & 5.88 & 13.95 \\
6. & Pouteria sp. & 0.04 & 6.45 & 0.25 & 5.88 & 12.33 \\
7. & Sterculia parkinsonii & 0.04 & 6.45 & 0.25 & 5.88 & 12.33 \\
8. & Dysoxyllum acutangulum & 0.02 & 3.23 & 0.25 & 5.88 & 9.11 \\
9. & Ficus sp. & 0.01 & 1.61 & 0.25 & 5.88 & 7.50 \\
& Jumlah & 0.62 & 100 & 4.25 & 100 & 200 \\
\hline
\end{tabular}

Sumber: Data Primer, 2015

Secara rinci dapat dilihat bahwa jenis Syzygium sp. adalah jenis yang memiliki Indeks Nilai Penting (INP) terbesar yaitu 59,01\%. Hal ini dapat ditunjukkan dengan nilai Frekuensi Relatif (FR) yang tinggi, yaitu $23,53 \%$ dan nilai Kerapatan Relatif (KR) yang tinggi pula yaitu $35,48 \%$. Elaeocarpus altiscatus menempati posisi kedua dengan Indeks Nilai Penting (INP) sebesar 39,66\% dengan Frekuensi Relatif (FR) 23,53\% dan Kerapatan Relatif 16,13\%. Pada posisi ketiga dengan Indeks Nilai Penting (INP) $26,28 \%$ adalah Rodamnia sp. dengan Frekuensi Relatif (FR) sebesar $11,76 \%$ dan Kerapatan Relatif (KR) $14,52 \%$. Dengan demikian dapat dilihat bahwa Syzygium sp. dan Elaeocarpus altiscatus memperlihatkan penyebaran yang sama yaitu pada nilai Frekuensi Relatif (FR) yang sama yaitu $23,53 \%$.
Ficus sp. merupakan jenis yang memiliki INP terendah yaitu 7,50\%.

b. Tingkat Pancang

Hasil dari analisis vegetasi untuk tingkat pancang pada sekitar persarangan burung pintar (Amblyornis inornatus) disajikan pada Tabel 3. Pada Tabel 3, menunjukkan bahwa pada fase ini Syzygium sp. masih mendominasi dengan Indeks Nilai Penting (INP) terbesar yaitu $112,50 \%$ yang diperlihatkan dengan Frekuensi Relatif (FR) sebesar 50,00\% dan Kerapatan Relatif (KR) $62,50 \%$. Pouteria sp. menempati posisi kedua dengan Indeks Nilai Penting (INP) sebesar 31,25\% dengan Frekuensi Relatif (FR) $12,50 \%$ dan Kerapatan Relatif (KR) $18,75 \%$. Jenis dengan nilai tertinggi ketiga yaitu Rodamnia sp. dengan Indeks Nilai Penting (INP) sebesar 18,75\% 
dengan Frekuensi Relatif (FR) 12,50\% dan Kerapatan Relatif (KR) 6,25\%. Dapat dilihat ada 3 jenis terendah yaitu
Rodamnia sp., Elaeocarpus altiscatus, dan Sterculia parkinsonii dengan INP masing-masing $18,75 \%$.

Tabel 3. Jenis, penyebaran dan indeks nilai penting vegetasi tingkat pancang pada sekitar persarangan burung pintar.

\begin{tabular}{llccccc}
\hline No. & Nama Jenis & K & $\begin{array}{c}\text { KR } \\
(\mathbf{\%})\end{array}$ & F & $\begin{array}{c}\text { FR } \\
\mathbf{( \% )}\end{array}$ & INP \\
\hline 1. & Syzygium sp. & 0.1 & 62.50 & 1.00 & 50.00 & 112.50 \\
2. & Pouteria sp. & 0.03 & 18.75 & 0.25 & 12.50 & 31.25 \\
3. & Rodamnia sp. & 0.01 & 6.25 & 0.25 & 12.50 & 18.75 \\
4. & Elaeocarpus altiscatus & 0.01 & 6.25 & 0.25 & 12.50 & 18.75 \\
$\mathbf{5 .}$ & Sterculia parkinsonii & 0.01 & 6.25 & 0.25 & 12.50 & 18.75 \\
& Jumlah & 0.16 & 100 & 2 & 100 & 200 \\
\hline
\end{tabular}

Sumber: Data Primer, 2015

c. Tingkat Tiang

Hasil dari analisis vegetasi untuk tingkat tiang pada sekitar persarangan burung pintar disajikan pada Tabel 4. Terlihat bahwa pada fase ini jenis Syzygium sp. masih mendominasi dengan Indeks Nilai Penting (INP) terbesar yaitu $202 \%$ yang terindikasi dengan Frekuensi Relatif(FR) sebesar $66,67 \%$ dan

\begin{abstract}
kerapatan Relatif (KR) 83,33\% serta Dominansi Relatif (DR) 51,65\%. Selanjutnya Litocarpus sp. dan Rodamnia sp. memiliki penyebaran yang sama, yaitu pada Indeks Nilai Penting (INP) sebesar 49\% dengan Frekuensi Relatif (FR) 16,67 \% dan Kerapatan Relatif (KR) $8,33 \%$ serta Dominansi Relatif(DR) 24,23\% yang sama.
\end{abstract}

Tabel 4. Jenis, penyebaran dan indeks nilai penting vegetasi tingkat tiang pada sekitar persarangan burung pintar.

\begin{tabular}{llcccccccc}
\hline No & Nama Jenis & K & $\begin{array}{c}\text { KR } \\
\mathbf{( \% )}\end{array}$ & F & $\begin{array}{c}\text { FR } \\
\mathbf{( \% )}\end{array}$ & LBD & D & $\begin{array}{c}\text { DR } \\
\mathbf{( \% )}\end{array}$ & $\begin{array}{c}\text { IN } \\
\text { P }\end{array}$ \\
\hline 1. & Syzygium sp. & 0.1 & 83.33 & 1.00 & 66.67 & 0.017 & 0.0000017 & 51.65 & 202 \\
2. & Litocarpus sp. & 0.01 & 8.33 & 0.25 & 16.67 & 0.008 & 0.0000008 & 24.23 & 49 \\
3. & Rodamnia sp. & 0.01 & 8.33 & 0.25 & 16.67 & 0.008 & 0.0000008 & 24.23 & 49 \\
& Jumlah & 0.12 & 100 & 1.5 & 100 & 0.032 & 0.0000032 & 100 & 300 \\
& & & & & & & & & \\
\hline
\end{tabular}

Sumber: Data Primer, 2015

Adapun 2 jenis yang memiliki INP terendah yaitu Litocarpus sp. dan Rodamnia sp. dengan nilai INP masingmasing $49 \%$.

\section{d. Tingkat Pohon}

Hasil dari analisis vegetasi untuk tingkat pohon pada sekitar persarangan burung pintar (Amblyornis inornatus) disajikan pada Tabel 5. terindikasi bahwa 
pada fase tingkat pohon, Syzygium sp. paling mendominasi dengan Indeks Nilai Penting (INP) terbesar yaitu 47,68\% yang diperlihatkan dengan Frekuensi Relatif (FR) sebesar 15,79\% dan Kerapatan Relatif (KR) 25,00\% serta Dominansi Relatif (DR) 6,89\%. Nilai tertinggi kedua ditunjukkan oleh Pouteria sp. dengan Indeks Nilai Penting (INP) yaitu 45,08\% yang terindikasi dengan Frekuensi Relatif (FR) sebesar 10,53\% dan Kerapatan Relatif (KR) 14,29\% serta Dominansi Relatif(DR) 20,27\%.

Tabel 5. Jenis, penyebaran dan indeks nilai penting vegetasi tingkat pohon pada sekitar persarangan burung pintar.

\begin{tabular}{llcccccccc}
\hline No. & Nama Jenis & K & $\begin{array}{c}\text { KR } \\
\mathbf{( \% )}\end{array}$ & $\mathbf{F}$ & $\begin{array}{c}\text { FR } \\
\mathbf{( \% )}\end{array}$ & LBD & D & $\begin{array}{c}\text { DR } \\
(\%)\end{array}$ & INP \\
\hline 1. & Syzygium sp. & 0.07 & 25.00 & 0.75 & 15.79 & 0.064 & 0.000006 & 6.89 & 47.68 \\
2. & Pouteria sp. & 0.04 & 14.29 & 0.50 & 10.53 & 0.189 & 0.000019 & 20.27 & 45.08 \\
3. & Drypethes sp. & 0.04 & 14.29 & 0.75 & 15.79 & 0.119 & 0.000012 & 12.84 & 42.91 \\
4. & Vitex pinnata & 0.03 & 10.71 & 0.50 & 10.53 & 0.105 & 0.000011 & 11.35 & 32.59 \\
5. & Dysoxyllum acutangulum & 0.02 & 7.14 & 0.25 & 5.26 & 0.155 & 0.000016 & 16.72 & 29.12 \\
6. & Sterculia parkinsonii & 0.02 & 7.14 & 0.50 & 10.53 & 0.049 & 0.000005 & 5.28 & 22.94 \\
7. & Podocarpus sp. & 0.02 & 7.14 & 0.50 & 10.53 & 0.049 & 0.000005 & 5.28 & 22.94 \\
8. & Rodamnia sp. & 0.01 & 3.57 & 0.25 & 5.26 & 0.067 & 0.000007 & 7.10 & 15.93 \\
9. & Prunus sp. & 0.01 & 3.57 & 0.25 & 5.26 & 0.062 & 0.000006 & 6.62 & 15.45 \\
10. & Dacrioides sp. & 0.01 & 3.57 & 0.25 & 5.26 & 0.041 & 0.000004 & 4.47 & 13.30 \\
11. & Elaeocarpus altiscatus & 0.01 & 3.57 & 0.25 & 5.26 & 0.031 & 0.000003 & 3.38 & 12.21 \\
& $\quad$ Jumlah & 0.28 & 100 & 4.75 & 100 & 0.931 & 0.000093 & 100 & 300 \\
\hline
\end{tabular}

Sumber: Data Primer, 2015

Jenis dengan nilai tertinggi ketiga yaitu Drypethes sp. dengan Indeks Nilai Penting (INP) yaitu 42,91\% yang diperlihatkan dengan Frekuensi Relatif (FR) sebesar $15,79 \%$ dan Kerapatan Relatif (KR) 14,29\% serta Dominansi Relatif (DR) 12,84\%. Elaeocarpus altiscatus merupakan jenis yang memiliki INP terendah yaitu $12,21 \%$.

\section{PEMBAHASAN}

Komposisi tumbuhan disekitar persarangan burung pintar menunjukan bahwa Syzygium sp. merupakan jenis dengan jumlah terbanyak pada semua fase pertumbuhan yaitu pada fase semai, pancang, tiang, dan pohon. Jumlah jenis pada fase pertumbuhan dipengaruhi oleh persaingan yang terjadi di antara setiap jenis individu untuk mendapatkan persediaan makanan (unsur hara, air, mineral), cahaya dan ruang tempat tumbuh. Persaingan yang demikian membentuk tipe-tipe tegakan hutan. Hal ini didukung oleh Soerianegara dan Indrawan (1982) yang mengemukakan bahwa persaingan akan menyebabkan terbentuknya susunan masyarakat tetumbuhan yang khas dari segi bentuk, jumlah jenis, dan jumlah individu penyusunannya, sesuai dengan keadaan tempat tumbuh atau habitatnya.

Parameter kuantitatif yang digunakan untuk mengkaji struktur tumbuhan 
memperlihatkan bahwa Syzygium sp. mendominasi seluruh kawasan pengamatan disekitar persarangan burung, yang ditunjukan oleh besarnya nilai kerapatan, frekuensi, dan tingkat penguasaan atau Indeks Nilai Penting (INP). Untuk kepentingan deskripsi suatu komunitas tumbuhan, Gopal \& Bhardwaj (1979) dalam Indriyanto (2006) berpendapat bahwa diperlukan minimal tiga macan parameter kuantitatif antara lain: densitas (kerapatan), frekuensi (jumlah), dan dominansi (penguasaan) tumbuhan.

Dari hasil pengolahan data, Syzygium sp. memiliki tingkat kerapatan tertinggi dari jenis lainnya untuk semua fase pertumbuhan. Hal ini menunjukan bahwa jenis Syzygium sp. memberikan pengaruh terhadap komunitas atau ekosistem sekitar persarangan. Indriyanto (2006) menjelaskan bahwa kerapatan merupakan salah satu hal yang menentukan pengaruh suatu populasi terhadap komunitas atau ekosistem dan juga dipakai untuk mengetahui perubahan yang terjadi dalam populasi.

Untuk jenis dengan frekuensi tertinggi pada tingkat pancang, tiang, dan pohon adalah Syzygium sp., sementara untuk frekuensi terendah tingkat pancang salah satunya adalah Pouteria sp. Kemudian pada tingkat tiang salah satunya yaitu Rodamnia sp. dan pada tingkat pohon salah satunya adalah Prunus sp. Frekuensi menggambarkan tingkat penyebaran jenis dalam habitat yang dipelajari. Semakin tinggi nilai frekuensinya maka semakin luas penyebarannya, sebaliknya semakin rendah nilai frekuensinya maka semakin sempit penyebarannya.

Syzygium sp. merupakan jenis dengan nilai dominansi tertinggi. Dominansi pada suatu jenis mengindikasikan penguasaan suatu daerah vegetasi dari suatu jenis tumbuhan. Jenis tumbuhan yang dominan memberi ciri utama terhadap fiognomi suatu komunitas hutan (Kusmana 1997). Ukuran dominansi dapat dinyatakan dengan beberapa parameter, antara lain biomassa, penutupan tajuk, luas basal areal, Indeks Nilai Penting (INP) dan perbandingan nilai penting (summed dominance ratio) (Indriyanto 2006).

Menurut Mueller-Dombois dan Ellenberg (1974), struktur tumbuhan dalam analisis vegetasi hutan dapat dinyatakan dalam bentuk Indeks Nilai Penting (INP). INP digunakan untuk mengetahui tingkat dominansi atau penguasaan suatu jenis dalam suatu komunitas. Jenis yang memiliki INP terbesar merupakan jenis yang paling dominan atau jenis tersebut mempunyai tingkat kesesuaian terhadap tempat tumbuh yang lebih baik dibandingkan dengan jenis lain. Selain itu, menurut Indriyanto (2006), di dalam masyarakat hutan, sebagai akibat adanya persaingan, jenis-jenis tertentu lebih berkuasa (dominan) dari pada jenis lainnya. Pohonpohon tinggi dari stratum (lapisan) teratas mengalahkan atau menguasai pohonpohon yang lebih rendah, dan merupakan jenis-jenis pohon yang mencirikan masyarakat hutan yang bersangkutan (Soerianegara \& Indrawan 2002).

Berdasarkan hasil penelitian, Syzygium sp. memiliki nilai INP tertinggi pada semua fase pertumbuhan. Sementara untuk INP terendah pada tingkat semai adalah Ficus sp., INP terendah tingkat pancang diwakili oleh tiga jenis yaitu Rodamnia sp., Elaeocarpus altaliscatus, dan Sterculia parkinsonii, pada INP terendah tingkat tiang diwakili 2 jenis yaitu Litocarpus sp. dan Rodamnia sp., 
dan INP terendah pada tingkat pohon adalah Elaeocarpus altaliscatus. Nilai INP tertinggi hingga terendah menunjukan urutan peranan atau penyesuaian jenis dalam persaingan pertumbuhan yang terjadi pada saat ini, sedangkan dimasa mendatang akan sangat tergantung pada faktor dan sifat semasa pertumbuhan secara keseluruhan. Secara umum, tumbuhan dengan INP tinggi mempunyai daya adaptasi, daya kompetisi dan kemampuan reproduksi yang lebih baik dibandingkan dengan tumbuhan yang lain.

Selanjutnya Hasil pengamatan menunjukan, tipe stratum yang ada disekitar persarangan burung pintar adalah tipe stratum B. Hal ini ditunjukan dengan bentuk tajuk yang bersambungan (kontinu) dan tinggi pohon-pohon yang berkisar antara 20-30 meter. Stratifikasi tajuk dapat digunakan untuk melihat pola pemanfaatan cahaya serta dapat pula digunakan untuk melihat jenis-jenis pohon yang dapat tumbuh dibawah naungan.

Menurut Sorianegara (1988), stratum B merupakan lapisan kedua dari stratifikasi tajuk yang terdiri dari pohonpohon dengan tinggi 20 sampai 30 meter. Bentuk tajuk dari pohon-pohon pada stratum ini kontinu, batang banyak bercabang dan bebas cabang tidak tinggi. Jenis-jenis yang mendominasi stratum B antara lain jenis Syzygium sp., Pouteria sp., Podocarpus sp., Prunus sp., Vitex pinnata, Drypethes sp., Elaeocarpus altiscatus dan Rodamnia sp. Sonbait et al. (2018) mengindikasikan beberapa jenis dari statum B juga menyusun struktur dan komposisi hutan di daerah Syoubri yang masih merupakan satu kawasan yang sama.
Kondisi lingkungan berperan penting dalam mempengaruhi pertumbuhan suatu vegetasi pada suatu wilayah. Pertumbuhan vegetasi banyak dipengaruhi oleh beberapa faktor tempat tumbuh seperti karakteristik umur tegakan, kerapatan tegakan, faktor iklim (temperatur, curah hujan, suhu udara, kelembaban udara dan sinar matahari), serta faktor tanah (komponen mikrobiologi tanah, komposisi bahan kimia dan sifat fisik tanah).

\section{DAFTAR PUSTAKA}

Bratawinata, 2001. Ekologi Hutan Hujan Tropis dan Metode Analisis Hutan. Departemen Pendidikan Nasional Direktorat Jendral Pendidikan Tinggi Badan Kerja Sama Perguruan Tinggi Negeri. Indonesia Timur.

Badan Pusat Statistik Provinsi Papua Barat. 2018. Papua Barat dalam angka. Provinsi Papua Barat. ISSN: 2089-1563.

https://papuabarat.bps.go.id/publicatio $\mathrm{n} / 2018 / 08 / 16 / 2947 \mathrm{ce} 6194 \mathrm{ea} 0 \mathrm{~b} 783082$ 85d6/provinsi-papua-barat-dalamangka-2018.html.

Indriyanto. 2006. Ekologi hutan. Bandar Lampung : Penerbit Universitas Lampung.

Kusmanan C. 1997. Metode survey vegetasi. Intstitusi Pertanian Bogor.

Kusmana C. 2001. Respon mangrove terhadap perubahan iklim global: Aspek Biologi dan Ekologi Mangrove. Bogor: Departemen Silvikultur Fakultas Kehutanan IPB.

Mueller-Dombois D and Ellenberg $\mathrm{H}$. 1974. Aims \& methods of vegetation ecology. NY: Wiley \& Sons.

Ramandey E. 1999. Analisis komposisi dan sruktur vegetasi pada tanah alfisol di areal bekas perladangan dan hutan 
utuh Kecamatan Sentani Timur Kabupaten Dati II Jayapura. Skripsi Sarjana Kehutanan Faperta Universitas Cendrawasih, (tidak diterbitkan).

Sonbait LY, Warmetan H, Manik H dan Cabuy RL. 2018. Inter-dependency of forest diversity and service towards the potency of ecotourism development in Pegunungan Arfak nature reserve. Ecology, Environment and Conservation, 24 (4): 1960-1965.

Soerianegara I dan Indarawan A. 1982. Ekologi hutan Indonesia. Dapartemen Manajemen Hutan. Fakultas Kehutanan Bogor. Bogor
Soerianegara I. 1988. Pengaruh pembebasan vertikal dan horisontal terhadap pertumbuhan regenerasi hutan pada tegakan bekas eksploitasi mekanisme di hutan Kalimantan Timur. Laporan LHP nomor 230. Bogor .

Soerianegara I dan Indarawan A. 2005. Ekosistem hutan Indonesia. Bogor : Laboratorium Teknologi Hutan, Fakultas Kehutanan IPB.

Soegianto A. 1994. Ekologi kuantitatif: Metode analisis populasi dan komunitas. Jakarta: Penerbit Usaha Nasional. 